\title{
Educação em saúde e promoção institucional nas revistas empresariais Essência e Unimed
}

\author{
Healthcare education and institutional promotion in organizational magazines \\ Essência and Unimed
}

\begin{abstract}
Felipe da Costa ${ }^{[a]}$, Valquíria Michela John ${ }^{[\mathrm{b}]}$
[a] Bacharel em Comunicação Social com habilitação em jornalismo e aluno da Pós-Graduação em Gestão em Comunicação Empresarial, ambos da Universidade do Vale do Itajaí (Univali), pesquisador associado do grupo de pesquisa Monitor de Mídia, Itajaí, SC - Brasil, e-mail: felipecosta@univali.br

[b] Jornalista, Mestre em Educação (UFSC), Doutoranda em Comunicação e Informação (UFRGS), professora do curso de Jornalismo da Univali, pesquisadora do Monitor de Mídia, Itajaí, SC - Brasil, e-mail: val@univali.br
\end{abstract}

\section{Resumo}

Este artigo visa a analisar quais as estratégias das reportagens de saúde publicadas nas revistas empresariais Essência e Unimed, ambas de Blumenau, SC. Foi utilizada, como metodologia, a Análise de Conteúdo e escolhidos como indicadores, educação em saúde, promoção da empresa, promoção de serviços e promoção de outras instituições. As duas revistas tiveram grande incidência para a educação em saúde, mas a Essência teve como destaque a promoção de serviços. Na pesquisa, chegamos à conclusão que, mesmo as revistas tendo como objetivo promover os serviços e as organizações, não deixam de ter como propósito educar seus leitores para uma melhor qualidade de vida.

Palavras-chave: Jornalismo empresarial. Jornalismo de saúde. Comunicação organizacional.

\section{Abstract}

This article aims to the analysis of the strategies of the healthcare articles published in the organizational magazines Essência and Unimed, both from Blumenau, SC. Content analysis was used as methodology, and Healthcare 
education, promotion of the company, Promotion of the services and the promotion of other institutions were chosen as indicators. Both magazines had a great incidence in Healthcare education, but Essência was more notable in the promotion of services. In this research, we have concluded that even though the magazines have the goal of promoting the organizations and their services, they still have the goal of educating their readership to have better quality of life.

Keywords: Organizational journalism. Healthcare journalism. Organizational communication.

\section{Introdução}

As publicações jornalísticas empresariais impressas adotam cada vez mais características dos veículos de comunicação tradicionais. A profissionalização da produção com jornalistas, que unem as técnicas utilizadas em qualquer redação com o marketing e a comunicação corporativa, faz surgir, além dos informativos destinados aos funcionários das empresas, revistas elaboradas e dedicadas aos variados segmentos de público das organizações.

As instituições estão percebendo que podem utilizar veículos jornalísticos para divulgar informações importantes, tanto para a empresa quanto para o público que deseja atingir. De acordo com o mercado de atuação, as publicações jornalísticas empresariais acabaram também se tornando veículos especializados em determinadas áreas, tratando, por exemplo, de assuntos como meio ambiente, saúde, educação, moda, entre diversas outras.

Como exemplo dessa segmentação, temos as revistas Essência e Unimed, publicadas por duas empresas de saúde da cidade de Blumenau ${ }^{1}$, Santa Catarina, que utilizam as publicações jornalísticas para divulgar material informativo destinado aos clientes das organizações e que, como veículos jornalísticos da área de medicina, também ajudam a promover a educação em saúde.

A revista Essência é produzida pelo Hospital Santa Catarina (HSC), um dos mais tradicionais da cidade de Blumenau. O HSC foi inaugurado em 27 de junho de 1920 pela Comunidade Luterana da cidade. O hospital atende 57 especialidades, o que resulta em uma média mensal de 3,7 mil acolhimentos no pronto-atendimento, 900 internações e 570 cirurgias, de baixa, média e alta complexidade ${ }^{2}$. A Essência é redigida e editada pela própria assessoria de imprensa do hospital, enquanto a arte e a diagramação são realizadas pela agência blumenauense "Escala, Metra". A revista tem 24 páginas e uma tiragem de 7.000 exemplares por edição.

A revista Unimed, por sua vez, é produzida pela cooperativa de médicos Unimed Blumenau, ligada a uma das maiores operadoras de planos de saúde do Brasil ${ }^{3}$. A instituição foi criada em 20 de setembro de 1971 pela Associação Médica de Blumenau. Hoje cobre 11 municípios do Vale do Itajaí e tem, aproximadamente, 618 médicos cooperados que atendem, aproximadamente, 90 mil clientes ${ }^{4}$. Os trabalhos de redação, edição, fotografia, arte e diagramação são responsabilidade da Mundi Editora ${ }^{5}$. A revista tem 36 páginas e uma tiragem de 4.000 exemplares.

1 Blumenau é uma cidade localizada em Santa Catarina, Região Sul do Brasil. A cidade é a terceira mais populosa do estado, com 309.214 habitantes (IBGE 2010). Na economia, Blumenau se destaca nos setores têxteis, informática e serviços (como educação e saúde).

2 Dados retirados do site <www.hsc.com.br>.

3 Segundo o site <www.Unimed.com.br>, "A Unimed é a maior experiência cooperativista na área da saúde em todo o mundo e também a maior rede de assistência médica do Brasil, presente em 83\% do território nacional”. O sistema tem 373 cooperativas médicas que atendem mais de 17 milhões de clientes e 73 mil empresas em todo país, detendo 37\% do mercado brasileiro.

4 Dados retirados do site <www. Unimedblumenau.com.br>.

5 A Mundi Editora é sediada na cidade de Blumenau e atua na assessoria e consultoria de comunicação e marketing. A empresa é a maior editora de revistas customizadas em Santa Catarina e edita cerca de 14 títulos entre revistas e boletins, além de produzir o jornal Folha de Blumenau.

Rev. Estud. Comun., Curitiba, v. 13, n. 30, p. 67-77, jan./abr. 2012 
O jornalismo de saúde, como o praticado nas revistas Essência e Unimed, é um dos principais pilares do jornalismo científico, que por sua vez é uma forma de divulgar a ciência para o público leigo, sendo ainda um dos assuntos que mais interessam aos brasileiros.

A pesquisa "percepção pública da ciência e tecnologia no Brasil", realizada em 2010 pelo Ministério da Ciência e Tecnologia, entrevistou 2.016 pessoas, entre homens e mulheres de todas as idades, e descobriu que os maiores interesses dos brasileiros são meio ambiente e medicina e saúde, empatados com $94 \%$ das citações dos entrevistados (MELO, 2011).

Apesar desse interesse, nem todas as matérias que tratam do tema saúde realizam a prática da educação em saúde, ou seja, abordar o assunto de forma que o sujeito possa, mais tarde, adquirir novos hábitos que evitem doenças e lhe traga uma melhor qualidade de vida.

Tratando-se de uma publicação empresarial, que visa dar a publicidade à empresa, temos duas situações: por um lado, a instituição quer se promover e a seus serviços, mas, por outro, por se tratar de um serviço essencial ao ser humano, deve também primar pela saúde de seus leitores.

Por isso, visamos, neste artigo, a identificar as estratégias que as revistas empresariais Essência e Unimed têm em vista ao publicar reportagens sobre saúde. Mais especificamente, se as publicações empresariais praticam a educação em saúde nas reportagens publicadas, além de promover as instituições e seus serviços.

Para realizar tal pesquisa, utilizamos como método a Análise de Conteúdo (BARDIN, 2004). Dentre as propostas da autora, usamos a técnica categorial, da qual escolhemos como indicadores, durante a pré-análise, a educação em saúde, a promoção da empresa, promoção de serviços e promoção de outras empresas. Apesar de acreditarmos que esta última não é propriamente um objetivo de uma empresa, encontramos algumas incidências durante as análises.

Determinamos como período de análise, seis edições de cada revista, equivalente às edições lançadas em janeiro, março, maio, julho, setembro e novembro de 2009. Assim, analisamos o total de 46 reportagens que tratavam de assuntos relacionados à saúde, sendo 17 da revista Essência e 29 da revista Unimed.

\section{Jornalismo como ferramenta de divulgação da empresa}

Francisco Torquato do Rego (1987) foi o primeiro brasileiro a estudar e conceituar o jornalismo empresarial. Para ele, tal especialização do jornalismo tem as mesmas características do jornalismo estabelecidas por Otto Groth - periodicidade, atualidade, difusão e universalidade.

A partir dessas características, o pesquisador diferencia as publicações com caráter jornalístico de outros tipos de publicações empresariais utilizadas tanto para a comunicação administrativa quanto para a comunicação mercadológica, como relatórios, folhetos, folders, cartas pessoais, comunicados, instruções, manuais de acolhimentos, circulares, apostilas, entre outras.

Das quatro características apontadas, a periodicidade é a mais importante para o jornalismo, pois determinará todas as especificações das outras. É ela também que, segundo Palma (1994,p. 104-105), vai garantir a vida do periódico:

Os objetivos e a vida saudável de um periódico institucional se mantém, entre outras coisas, com a firme decisão e a inviolabilidade de uma rígida periodicidade. A periodicidade, não importam os percalços que por ventura se apresentem, deverá ser rigorosa. $\mathrm{O}$ descrédito e a consequente morte do jornal, será o preço da não observância deste aspecto.

Por não serem comercializadas, as publicações jornalísticas empresariais têm a periodicidade mais espaçada do que os meios jornalísticos denominados massivos. A difusão, portanto, tem um tempo maior do que em outros veículos.

Enquanto um jornal tem um tempo de vida limitadoa24horas, pois no dia seguinteaparecerá outro, a publicação empresarial, por sua periodicidade e por seu sistema de distribuição, tem um limite de duração muito longo (REGO, 1987, p. 42).

Com o tempo maior de circulação do material, a publicação empresarial vai trabalhar, no quesito atualidade, com informações que não sejam tão factuais. Tomados esses cuidados, evita-se que o receptor leia uma informação que já não tenha mais validade. 
Já a universalidade, segundo o autor, “deve ser entendida como todo o acervo de mensagens, de qualquer área, que possa interessar à empresa ou à comunidade" (REGO, 1987, p. 41). A partir dessas características, o autor definiu que as publicações jornalísticas empresariais impressas podem se apresentar nos meios boletim, jornal e revista.

Para Rêgo (1987), as revistas empresariais têm, geralmente, mais de 20 páginas e uma periodicidade no mínimo bimestral. O suporte permite utilizar mais ilustrações e aperfeiçoar a arte, além de ter maior variedade temática. Graças ao intervalo maior entre uma edição e outra, as revistas precisam investir em textos que fujam da factualidade e tenham um interesse mais permanente.

Falando sobre ojornalismo de revista, Scalzo (2003, p. 14) resume essas ideias em poucas palavras: "Revista une e funde entretenimento, educação, serviço e interpretação dos acontecimentos. Possui menos informação no sentido clássico (as "notícias quentes") e mais informação pessoal (aquela que vai ajudar o leitor em seu cotidiano, em sua vida prática)". Assim, as revistas empresariais tornam-se ideais para apresentar matérias mais aprofundadas e que priorizem um caráter interpretativo. Fator, aliás, que é característico do jornalismo de revista em seus outros segmentos.

Rego (1987) afirma que as publicações organizacionais são utilizadas para a promoção da imagem das empresas junto aos seus públicos. Sólio (2008,p. 76) complementa: "O jornal organizacional é um veículo importante para a divulgação da cultura, da política e da ideologia da organização e deve ser usado estrategicamente."

Utilizar o jornalismo empresarial de forma estratégica, para Alvarenga (2010), é adotar os princípios da prática do jornalismo convencional, com fidedignidade, liberdade de imprensa e equilíbrio. O jornalismo empresarial une, portanto, as qualidades do jornalismo praticado nos meios de comunicação de massa tradicionais, com matérias que possam trazer visibilidade a produtos ou serviços e que sejam ainda de interesse do leitor.

\section{O papel educativo do jornalismo cientifico}

Todo dia a ciência faz novas descobertas. As novidades precisam então ser difundidas para que possam serainda mais estudadas, ou tero conhecimento aplicado. Há duas formas de fazer esta difusão científica. A primeira é comunicação científica e é destinada aos especialistas, geralmente escrita em uma linguagem que poucas pessoas que não são da área entenderiam.

Já a divulgação científica é orientada para o público leigo, mas tem interesse nos assuntos científicos. Essa divulgação, que pode ser tanto das chamadas ciências básicas, aplicadas ou humanas, pode ser realizada por diversos meios. Bertolli Filho (2006) cita como exemplo

obras de literatura e poesia, livros didáticos, jogos, estórias escritas e/ou contadas para a recreação infantil, histórias em quadrinho, filmes, programas de rádio e televisão, sítios virtuais, apresentações teatrais, músicas, exposições em museus, dentre outras.

Albagli (1996, p. 396) menciona três objetivos que orientam a prática da divulgação científica: educacional, cívico e mobilização social. Segundo a autora, o educacional amplia o conhecimento e a compreensão do público leigo acerca do processo da ciência, assim como de sua lógica. O cívico amplia a consciência do cidadão a respeito de questões sociais, econômicas e ambientais que se associam ao desenvolvimento da ciência e tecnologia. Já o de mobilização popular aumenta a possibilidade do cidadão bem informado e com opinião formada participar da sociedade e das políticas públicas. $\mathrm{Na}$ mesma linha, Oliveira (2007, p. 13) destaca a importância da divulgação científica para a cidadania:

[...] o acesso às informações sobre C\&T é fundamental para o exercício pleno da cidadania e, portanto, para o estabelecimento de uma democracia participativa, na qual grande parte da população tenha condições de influir, com conhecimento, em decisões e ações ligadas a C\&T.

Apesar de haver diversas maneiras de divulgar a ciência, nosso interesse nesta pesquisa é tratar de um caso específico, a divulgação científica realizada pormeio do jornalismo científico, que segundo Bueno (1984 apud BERTOLLI FILHO, 2006, p. 4) é:

Um caso particular de divulgação científica e [que] refere-se a processos, estratégias, técnicas 
e mecanismos para veiculação de fatos que se situam no campo da ciência e da tecnologia. Desempenha funções econômicas, político-ideológicas e socioculturais importantes e viabiliza-se, na prática, através de um conjunto diversificado de gêneros jornalísticos.

O jornalismo pode tornar-se uma excelente maneira de popularizar os assuntos da ciência. Albagli (1996,p. 400) acredita que "[...] o jornalismo científico permanece sendo o veículo mais tradicional para a divulgação da ciência e a transmissão de informação científica para o público leigo".

Além do tradicionalismo, também devemos levar em consideração a abrangência que o jornalismo pode ter. A divulgação científica a partir do jornalismo pode envolver um número maior de pessoas com o número menor de mensagens emitidas de uma vez. Diferente, por exemplo, de exposições em museus de ciência, em que o guia precisa repetir a mesma mensagem para diversos grupos de visitantes. Ivanissevich (2005, p. 14) destaca que "os meios de comunicação são o caminho mais imediato e abrangente de intensificar a divulgação científica para o grande público".

Outro papel importante do jornalismo científico é o de educar para a ciência. Melo (2006, p. 119) afirma que "Nos países subdesenvolvidos, a tarefa principal do jornalismo é educar as grandes massas para que possam assumir o seu papel de sujeito da história. Isso significa acesso ao conhecimento, participação política e mobilização social". Segundo o autor, o jornalismo científico:

Deve ser uma atividade principalmente educativa. Deve ser dirigido à grande massa da população e não apenas à sua elite. Deve promover a popularização do conhecimento que está sendo produzido em nossas universidades e centros de pesquisa, de modo a contribuir para a superação dos muitos problemas que o povo enfrenta. Deve utilizar uma linguagem capaz de permitir o entendimento das informações pelo cidadão comum. Deve gerar o desejo do conhecimento permanente, despertando o interesse pelos processos científicos enão pelos fatos isolados e seus personagens. Deve discutir a política científica, conscientizando a população que paga impostos para participar das decisões sobre a alocação de recursos que significam o estabelecimento de prioridades na produção do saber. Deve realizar um trabalho de iniciação dos jovens ao mundo do conhecimento e de educação continuada dos adultos (MELO, 2006, p. 118).

Dentro do jornalismo científico, um caso particular e, provavelmente, o mais importante, segundo Bueno (2011b), é o jornalismo de saúde:

a importância do jornalismo em saúde tem a ver com o fato de que, na verdade, a saúde é o maior patrimônio do ser humano e que, em função disso, as notícias que envolvem esta temática geralmente seduzem os leitores, telespectadores, radiouvintes e internautas.

Segundo Caldas (2010), a divulgação científica na área da saúde é uma das mais lidas. A autora afirma que o grande interesse está diretamente associado à responsabilidade social da comunicação, e que, por esse motivo, não deve ser explorada de forma sensacionalista e deve considerar aspectos preventivos e não apenas de cura de enfermidades. A autora considera a comunicação para a saúde um processo educativo.

"Entende-se por educação em saúde quaisquer combinações de experiências de aprendizagem com vistas a facilitar ações voluntárias conducentes à saúde" (CANDEIAS, 1997, p. 210). Conforme explicam os dinamarqueses Meillier, Lund e Gerdes (1997 apud BUENO et al., 2010c):

A divulgação em saúde cumpre uma função indireta na mudança dos hábitos de vida, mantendo o conhecimento já adquirido e provendo novas informações. Quando os assuntos de saúde são colocados em pauta, como resultado de uma discussão ou experiências pessoais, esse conhecimento ajuda a formar o modo de reação dos indivíduos às situações que têm de enfrentar ao longo da vida. [...] Por causa do peso que tem o conhecimento experimental nas tomadas de decisão pessoais, é particularmente importante, para a prevenção, mostrar o conhecimento teórico sobre o que é saudável e o que não é relacionando-o a experiências individuais. Isso significa que a informação veiculada através dos meios de comunicação de massa não inicia o processo cognitivo, mas serve como uma fonte a mais no input de base afetiva. 
Ou seja, o objetivo da educação em saúde é informar o cidadão, visando a que ele relacione os dados com sua vida e, mais tarde, possa mudar suas atitudes e comportamentos.

\section{Estratégias de comunicação das reportagens nas revistas empresariais}

Se, para o jornalismo tradicional, praticar a educação científica, como afirma Melo (2006), é um dever, principalmente na área de saúde pela importância que ela tem (BUENO, 2011b; CALDAS, 2010), para o jornalismo empresarial, é também uma estratégia de comunicação para as empresas de saúde.

Praticando a educação em saúde, as empresas adotam os princípios do jornalismo convencional, um dos critérios citados por Alvarenga (2010) para utilizar o jornalismo empresarial de forma estratégica, sem, com isso, deixar de divulgar a cultura, política e ideologia da organização (SÓLIO, 2008), e ainda promover a imagem da organização (REGO, 1987).

Na revista Essência, encontramos um total de 13 reportagens que praticavam a educação em saúde. Como exemplo, citamos a reportagem publicada na edição 84, "Mexa-se e previna a trombose". A reportagem inicia falando sobre o que pode acontecer quando o organismo não está em equilíbrio, conforme a seguinte citação:

A questão alimentação equilibrada e a prática regular de atividade física são apenas alguns dos requisitosimportantes para a plena saúde. Porém, no dia a dia outros cuidados são essenciais para evitar o surgimento de doenças que, às vezes, podem levar um bom tempo para serem resolvidas. Um exemplo é a trombose venosa. Mas antes de entrar em detalhes sobre essa patologia, é importante você saber que nosso corpo é dotado de mecanismos que possuem funções muito bem específicas para mantê-lo em constante equilíbro. Eé no líquido vermelho, que circula em nossas veias, que existem diversos fatores que criam as condições certas para favorecer a coagulação do sangue. Ou seja, a capacidade de ele se solidificar ao ocorrer uma ruptura vascular. Contudo, quando o organismo está em descompasso e passa por alterações, pode haver o surgimento de trombos em locais em que não houve sangramento. As massas sólidas se formam no interior dos vasos dos membros inferiores, na maioria das vezes, e são denominadas de trombose. Segundo o angiologista Enzo Luiz Sugayama Campanella, a trombose pode ocorrerem uma veia logo abaixo da pele ou surgir nas veias profundas, no interior dos músculos. "Independentemente da localização, o trombo provoca uma inflamação, que pode permanecer apenas no local inicial de seu desenvolvimento ou se estender ao longo da veia afetada, provocando a obstrução parcial ou total da mesma", explica (SANTANA, 2009b, p. 17).

O texto segue com a explicação de como se realiza o diagnóstico. Depois continua com os sintomas e o que fazer caso os tenha, ressaltando após a importância da prevenção:

Para a maioria das pessoas, o simples fato de caminhar é uma grande ajuda na prevenção da trombose venosa. Então, mexa-se! Sempre que for possível, não fique muito tempo parado na mesma posição. [...] Por isso, antes que você faça parte dessa realidade, ao primeiro sinal de dor intensa, inchaço, vermelhidão, aumento da temperatura das pernas, endurecimento da musculatura e formação de nódulos dolorosos nas varizes, consulte um angiologista. E o melhor de tudo: previna-se! (SANTANA, 2009b, p. 17)

Já na revista Unimed, encontramos um total de 27 reportagens que faziam educação para a saúde. Demonstramos a seguir a reportagem "Sinais indicam possíveis problemas", veiculada na edição 43. O texto demonstra que a educação para a saúde pode ser realizada mesmo que o leitor não seja a pessoa que irá se beneficiar. Cita motivos que podem causar problemas auditivos, sinais que podem aparecer e que podem ter resultados futuros no aprendizado e desenvolvimento das crianças e afirma que se os sinais de surdez forem observados no primeiro ano de vida, o problema tem grande chance de ser solucionado:

O sistema auditivo é um dos responsáveis pelo aprendizado e desenvolvimento das crianças. Por isso é preciso atenção a possíveis falhas, que podem ocorrer por vários fatores. [...] Para detectar problemas nesse processo, pais e 
professores devem estar atentos aos sinais que indicam alguma desordem no desenvolvimento auditivo e de linguagem. Ações como atentar, discriminar, reconhecer, recordar ou compreender informações auditivas, assim como o volume excessivo da televisão e a dificuldade do aprendizado na escola devem servir de parâmetro. Crianças que não têm o aparelho auditivo desenvolvido corretamente também podem apresentar baixa autoestima, depressão, isolamento e desinteresse pelo estudo. De acordo com o otorrinolaringologista Guilherme Melo, os primeiros anos de vida são uma fase de aprendizado e conhecimento do mundo. Além da observação, quando é detectado algum sintoma de falha na audição, é recomendado o exame de audiometria, que pode ser feito por um otorrinolaringologista ou fonoaudiólogo. Com o diagnóstico, o fonoaudiólogo é o profissional que irá trabalhar o desenvolvimento das habilidades dessa criança, ajudando-a a alcançar êxito nas atividades escolares, já que não se trata de um problema pedagógico e sim de percepção auditiva e desenvolvimento linguístico. [...] Segundo a Sociedade Brasileira de Otologia, quase $100 \%$ dos casos de surdez infantil têm algum tipo de solução quando diagnosticados no primeiro ano de vida (SINAIS, 2009, p. 30-31).

Na revista Essência, encontramos seis reportagens que promoviam a empresa. Como foi o caso da reportagem "Uma questão de escolha", veiculada na edição 87. O texto que fala da dificuldade de parar de fumar e dos benefícios que esta prática traz à saúde também promove a instituição demonstrando a medida tomada pelo Hospital Santa Catarina:

O cerco aos fumantesé uma realidade em muitos países, e o Brasil segue a mesma tendência. No Estado de São Paulo, por exemplo, é proibido fumar em qualquer lugar coletivo fechado ou semiaberto. Já em Santa Catarina, tramita no legislativo o Projeto de Lei no 273/2008, para a proibição do consumo de cigarros, cigarrilhas, charutos ou de qualquer outro produto fumígeno, derivado ou não do tabaco, em ambientes de uso coletivo, públicos ou privados. Assim, mesmo antes de existir o Projeto de Lei, o Hospital Santa Catarina de Blumenau
(HSC Blumenau) saiu na frente. Desde 2005, a Instituição tem um Comitê de Controle do Tabagismo que, além de desenvolver o Plano Antitabagismo, tem como responsabilidade aplicar as ações dentro do cronograma estabelecido. E desde junho deste ano, a aplicação do Plano está ainda mais efetiva, pois a partir do dia $1^{\circ}$ de janeiro de 2010 , será proibido fumar em qualquer local, dentro das dependências do HSC Blumenau, inclusive na área externa. Como essa determinação atinge clientes, pacientes internados - com exceção dos com indicação -, colaboradores, membros do Corpo Clínico e profissionais terceirizados, várias ações serão promovidas até o mês de dezembro. Por isso, é importante ficar atento. E lembre-se de que essa proibição será instituída com o objetivo de garantir um ambiente mais saudável para todas as pessoas que utilizam os serviços do HSC Blumenau, bem como dos profissionais que aqui atuam para cuidar de sua saúde. Então, que tal aproveitar para fazer novas escolhas e quem sabe pararde fumar? (SANTANA, 2009c, p. 15)

$\mathrm{Na}$ revista Unimed, duas reportagens promoveram a instituição. No texto "Teste da orelhinha detecta problemas de audição", publicado na edição 39, essa intenção fica evidente, principalmente pelo fato de fazer um exame que não é obrigatório por lei, mas que é importante para a saúde do bebê:

A Unimed passa a oferecer o teste, mesmo sem a obrigatoriedade, a partir de dezembro de 2008, para todos os clientes, independente de possuírem o plano regulamentado ou não regulamentado, sem cobrança de coparticipação. Todo recém-nascido deverá fazer o exame ainda nos primeiros 15 dias de vida para detectar se há déficit auditivo (TESTE, 2009, p. 27).

A revista Essência realizou a promoção de serviços em oito reportagens. Uma delas foi o texto "Estar bem de saúde vai além de estar bem fisicamente", da edição 86, que fala a respeito da psicologia hospitalar realizada no Hospital Santa Catarina:

A tradição dos cuidados com a vida emocional dos pacientes no Hospital Santa Catarina de Blumenau (HSC Blumenau) vem ao longo de 
uma história de 40 anos, com a instalação da Unidade Psiquiátrica, por Dr. Hercílio Luz Costa. Conhecida atualmente como Clínica de Saúde Mental, conta com uma equipe formada por médicos psiquiatras e profissionais de Psicologia. De acordo com o Psiquiatra e coordenador da Clínica de Saúde Mental, Dr. Otmar Steiner, a psicologia hospitalar, no HSC Blumenau, também passou a ser uma realidade e está disponível nos serviços de Cardiologia, Oncologia, Centro de Terapia Intensiva (CTI Adulto) e Unidade de Terapia Intensiva Neonatal e Pediátrica (UTIN-PED). "O objetivo é ampliar o serviço para outras unidades. As angústias e medos necessitam de escuta atenta e de alguém que esteja preparado para ajudara elaborar o sofrimento. Daíaimportância do psicólogo nas equipes assistenciais dentro do Hospital", relata. Então, para um melhor acompanhamento dos pacientes, todas as semanas a equipe se reúne para discutir os casos e ouvir a opinião dos demais profissionais. Porque cada detalheéimportante para melhorara qualidade de vida da pessoa internada, além de tornar a estada do paciente no Hospital ainda mais confortável (SANTANA; SOUZA, 2009, p. 9).

Já na revista Unimed, foram encontrados três textos que promoviam serviços da instituição. A reportagem "Uma campanha que salva vidas" é um exemplo da promoção dos serviços, pois fala da campanha contra o câncer de mama que a instituição promove, conforme citamos a seguir no trecho da reportagem:

Aos 76 anos, Artena Pellens encontrou na Unimed seus dois anjos da guarda. Ela conta que, por meio do Programa de Prevenção do Câncer de Mama, recebeu, no fim de 2007, uma carta que a convidava para fazer o exame de mamografia. Em seguida, os funcionários do Setor de Medicina Preventiva da Unimed, Fernando Eskelsen do Nascimento e Fábia Luíza Sestrem entraram em contato por telefone para incentivar a ação (UMA, 2009, p. 19).

A última categoria analisada foi a promoção de outras instituições, que na revista Essência foi veiculada em três reportagens. Como foi o caso do texto “Mas o que é glúten”, edição 86, que traz o seguinte quadro com locais que vendem produtos sem glúten (Figura 1).

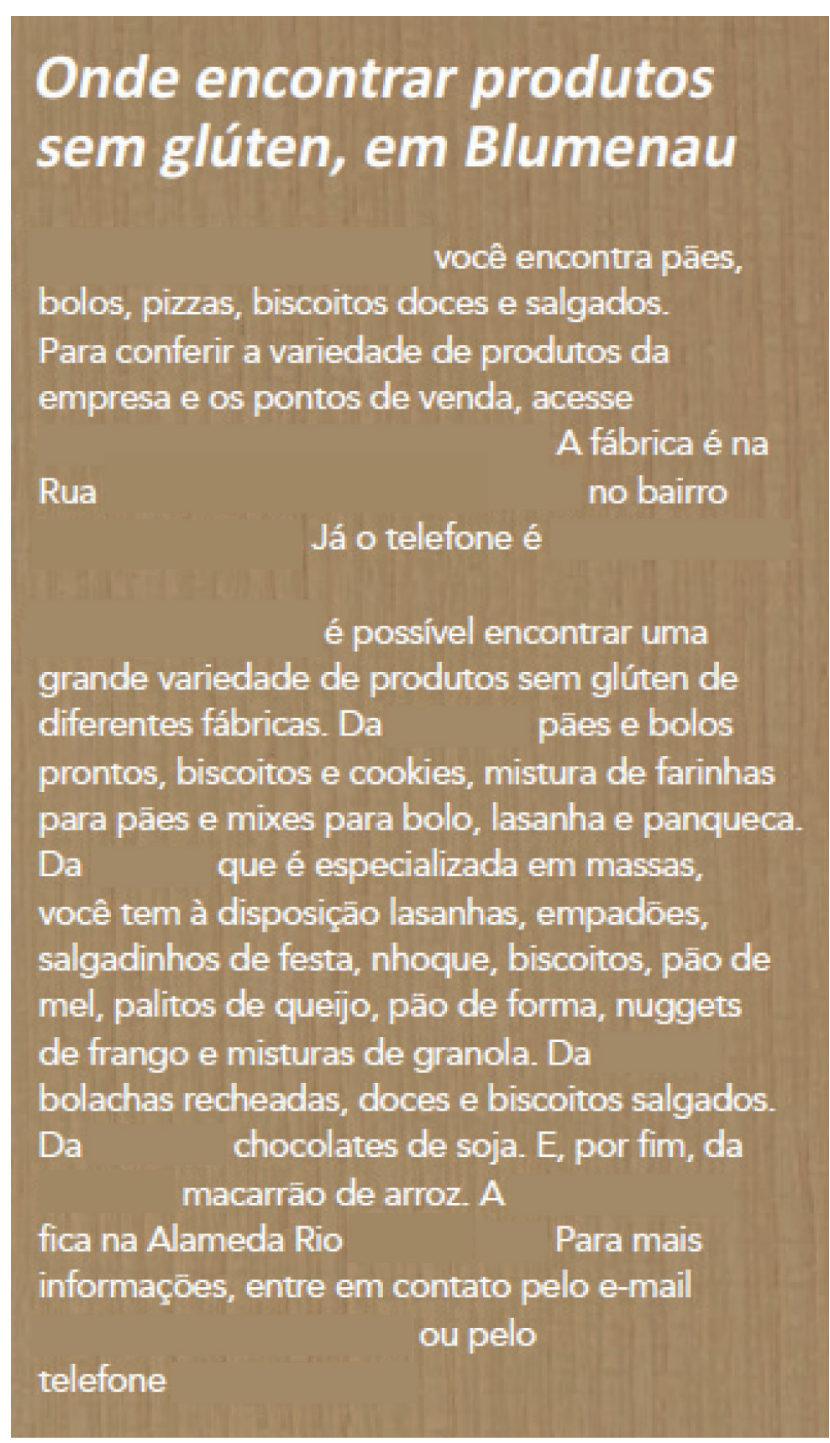

Figura 1 - Exemplo de promoção de outras instituições na revista Essência

Fonte: SANTANA, 2009a, p. 15.

A revista Unimed realizou a promoção de outras instituições em apenas dois textos. A reportagem "Em busca da perfeição espiritual", publicada na edição 39, foi um dos casos, já que relata sobre uma nova prática de yoga realizada em Blumenau, como pode ser observado a seguir: 
A nova modalidade foi apresentada aos blumenauenses no encontro dos praticantes no início de outubro, no Jardim do Yoga, no bairro Ponta Aguda. Cercade60 pessoas, de variadasfaixas etárias, mostraram-seatraídas em conhecerapráticamilenar chinesa que se estrutura na tríade Zhen, Shan e Ren: verdade, bondade e tolerância (EM, 2009, p. 14).

As tabelas com a quantidade de cada objetivo encontrado nas reportagens das revistas Essência e Unimed podem ser conferidas nas Tabelas 1 e 2.

\section{Considerações finais}

Com a análise das estratégias de comunicação das reportagens sobre saúde das revistas empresariais Essência e Unimed, percebemos, respaldados nos dados coletados e já apresentados, que tanto o Hospital Santa Catarina quanto a Unimed Blumenau utilizam as reportagens das revistas estrategicamente para educar os leitores para que tenham uma vida mais saudável, sem com isso deixar de promover o nome da instituição e de seus serviços.

Tabela 1 - Objetivos encontrados nas reportagens da revista Essência

\begin{tabular}{lccccccc}
\hline Objetivos & Ed. 84 & Ed. 85 & Ed. 86 & Ed. 87 & Ed. 88 & Ed. 89 & Total \\
\hline $\begin{array}{l}\text { Educação } \\
\text { para a saúde }\end{array}$ & 2 & 2 & 2 & 3 & 2 & 2 & 13 \\
$\begin{array}{l}\text { Promoção } \\
\text { da empresa }\end{array}$ & 1 & 1 & - & 2 & 1 & 1 & 6 \\
$\begin{array}{l}\text { Promoção } \\
\text { de serviços }\end{array}$ & 1 & 1 & 3 & 1 & 1 & 1 & 8 \\
$\begin{array}{l}\text { Promoção } \\
\text { de outras } \\
\text { instituições }\end{array}$ & 1 & - & 1 & - & 1 & - & 3 \\
\hline
\end{tabular}

Fonte: Dados da pesquisa.

Tabela 2 - Objetivos encontrados nas reportagens da revista Unimed

\begin{tabular}{lccccccc}
\hline Objetivos & Ed. 39 & Ed. 40 & Ed. 41 & Ed. 42 & Ed. 43 & Ed. 44 & Total \\
\hline $\begin{array}{l}\text { Educação } \\
\text { para a saúde }\end{array}$ & 5 & 2 & 9 & 4 & 4 & 3 & 27 \\
$\begin{array}{l}\text { Promoção } \\
\text { da empresa }\end{array}$ & 1 & - & 1 & - & - & - & 2 \\
$\begin{array}{l}\text { Promoção } \\
\text { de serviços }\end{array}$ & 2 & - & 1 & - & - & - & 3 \\
$\begin{array}{l}\text { Promoção } \\
\text { de outras } \\
\text { instituições }\end{array}$ & 2 & - & - & - & - & - & 2 \\
\hline
\end{tabular}

Fonte: Dados da pesquisa. 
É importante salientar que a intenção de promover uma instituição, ou de promover seus serviços, não anula a possibilidade de realizar a educação para a saúde. Em muitas reportagens, tanto da revista Essência quanto da Unimed, houve o caso das três categorias terem aparecido na mesma matéria.

A grande incidência da estratégia educação para a saúde demonstra que ambas as instituições se preocupam também com a saúde dos leitores, que são seus próprios clientes. Além disso, as informações também beneficiam as empresas, de acordo com a natureza de negócios que elas se prestam a realizar.

A revista Essência tem como segunda estratégia com maior número de incidência a promoção de serviços. Por ser produzida por um hospital, acreditamos que é natural que a empresa queira demonstrar os seus serviços, uma vez que a renda para manter o hospital vem dos exames, cirurgias e demais procedimentos realizados.

A revista Unimed teve uma grande diferença entre a educação para a saúde para as demais estratégias listadas. Se os leitores começarem a adotar as práticas mais saudáveis, aumenta a possibilidade de ainstituição obter lucro. Já que, se o usuário não fica doente, ele não precisa utilizar o plano com consultas ou exames. Podemos verificar essa situação na notícia publicada na edição 43, em que diz que foram identificados 11 casos de câncer de mama em fase inicial e que "o programa de prevenção também trouxe economia para a Unimed Blumenau, pois, em casos avançados, o tratamento para cada caso de câncer de mama custa, em média, R\$100 mil para as operadoras de saúde”.

Outro dado importante que percebemos, comparando as duas análises realizadas, é que nenhuma das duas revistas realiza uma prática comum no jornalismo de saúde brasileiro, que é manter o foco na doença. Segundo Bueno (2010a),

ao concentraremo foco na doença, essas matérias não permitem a elaboração de uma proposta informativa que privilegie a prevenção, a educação para a saúde e o debate sobre as condições econômicas e socioculturais que podem conduzir a uma melhor qualidade de vida.

Além de a maioria das reportagens manter seu foco na prevenção e ter como estratégia a educação para a saúde, observamos a pouca incidência de matérias que relacionavam-se ao risco de morte.
Por fim, acreditamos que, com este estudo, demonstramos que o Hospital Santa Catarina e a Unimed Blumenau utilizam as reportagens de saúde, veiculadas em suas respectivas revistas, como forma de divulgar sua marca, sua cultura e sua política. Entretanto, também como uma importante ferramenta para se aproximar de seus clientes trazendo informações, em forma de jornalismo, que podem gerar benefícios tanto para a empresa quanto para seus clientes.

\section{Referências}

ALBAGLI, S. Divulgação científica: informação para a cidadania? Ciência da Informação, v. 25, n. 3, p. 396-404, 1996.

ALVARENGA, M. O fim do jornalzinho. Disponível em: $<$ http:/ / www.abracom.org.br/descricao.asp?id=14>. Acesso em: 6 jun. de 2010.

BARDIN,L. Análise de conteúdo.Lisboa:Edições 70,2004.

BERTOLLI FILHO, C. Elementos fundamentais para a prática do jornalismo científico. 2006. Disponível em: <http://www.bocc.ubi.pt>. Acesso em: 6 mar. 2010.

BUENO, W. da C. Comunicação para a saúde: uma revisão crítica. Portal do Jornalismo Científico. Disponível em: $<$ http://www.jornalismocientifico.com.br>. Acesso em: 29 de maio 2010a.

BUEnO, W. da C. Jornalismo em saúde. Portal do Jornalismo Científico. Disponível em: <http://www. jornalismocientifico.com.br>. Acesso em: 29 maio 2010b.

BUENO, W. da C. et al. Divulgação da saúde na imprensa brasileira: expectativas e ações concretas. Portal do Jornalismo Científico. Disponível em: <http://www. jornalismocientifico.com.br>. Acesso em: 29 maio 2010c.

BURKETT, W. Jornalismo científico: como escrever sobre ciência, medicina e alta tecnologia. Rio de Janeiro: Forense Universitária, 1990.

CALDAS, G. Comunicação da saúde. In: SOCIEDADE BRASILEIRA DE ESTUDOS INTERDISCIPLINARES DA COMUNICAÇ̃̃O - INTERCOM. Enciclopédia Intercom de Comunicação. São Paulo: Sociedade Brasileira de Estudos Interdisciplinares da Comunicação, 2010. p. 251-252. 
CANDEIAS, N. M. F. Conceitos de educação e promoção em saúde: mudanças individuais e mudanças organizacionais. Revista Saúde Pública, v. 31, n. 2, p. 209-213, 1997. doi.org/10.1590/S0034-89101997000200016

EMBUSCA da perfeição espiritual. Unimed, Blumenau, n. 39, p. 14, 2009.

FRANÇA, M. San J. Divulgação ou jornalismo: duas formas de abordar o mesmo assunto. In: VILASBOAS, S. (Org.). Formação e informação científica: jornalismo para iniciados e leigos. São Paulo: Summus, 2005.

HERSCOVITZ, H. G. Análise de conteúdo em jornalismo. In: BENETTI, M.; LAGO, C. Metodologia de pesquisa em jornalismo. Petrópolis: Vozes, 2007. p. 123-142.

IVANISSEVICH, A. A mídia como intérprete: como popularizar a ciência com responsabilidade e sem sensacionalismo. In: VILASBOAS, S. (Org.). Formação e informação científica: jornalismo para iniciados eleigos. São Paulo: Summus, 2005. p. 13-30.

MELO, J. M. de. Jornalismo opinativo. Campos do Jordão: Mantiqueira, 2003.

MELO, J. M. de. Teorias do jornalismo: identidades brasileiras. São Paulo: Paulus, 2006.

MELO, M. M. Estudo do MCT mostra interesse do brasileiro por ecologia, saúde e ciências. Correio Brasiliense. Disponível em: < http:/ /www.correiobraziliense.com.br/ app/noticia/ciencia-e-saude/2011/01/22/interna_ciencia_saude,233663/estudo-do-mct-mostra-interesse-do-brasileiro-por-ecologia-saude-e-ciencia.shtml>. Acesso em: 6 mar. 2011.

OLIVEIRA, F. Jornalismo científico. São Paulo: Contexto, 2007.
PALMA, J. R. Jornalismo empresarial. Porto Alegre: Sagra-DC Luzatto, 1994.

REGO, F. G. T. do. Jornalismo empresarial: teoria e prática. São Paulo: Summus, 1987.

SANTANA, C. Mas o que é glúten?. Essência, n. 86, p. 8-9, 2009a.

SANTANA, C. Mexa-se e previna a trombose venosa. Essência, n. 84, p. 16-17, 2009b.

SANTANA, C. Uma questão de escolha. Essência, n. 87 , p. $12-15,2009$ c.

SANTANA, C.; SOUSA, A. P. de. Estar bem de saúde vai além de estar bem consigo fisicamente. Essência, n. 86, p. 12-15, 2009.

SCALZO, M. Jornalismo de revista. São Paulo: Contexto, 2003.

SINAIS indicam possíveis problemas. Unimed, n. 43, p. 30-31, 2009.

SÓLIO, M. B. Jornalismo organizacional: produção e recepção. Caxias do Sul: Educs, 2008.

TESTE da orelhinha detecta problemas de audição. Unimed, n. 39, p. 26-27, 2009.

Uma campanha que salva vidas. Unimed, n. 39, p.19, 2009.

Recebido: 31/03/2012

Received: 03/31/2012

Aprovado: 01/06/2012

Approved: 06/01/2012 
